\title{
Diagnosis of Parkinson's Disease Type 1 and 2 on the Electrical Activity of Hand Muscle During Isometric Contraction With and Without Intellectual Activity
}

\author{
Roya Sotoodeh $^{\mathbb{D}}$, Fereidoun Nowshiravan Rahatabad* ${ }^{\circledR}$, Nader Jafarnia Dabanloo \\ Department of Biomedical Engineering, Science and Research Branch, Islamic Azad University, Tehran, Iran
}

\begin{abstract}
Background: Parkinson's disease (PD) is the third most common neurodegenerative disease in the central nervous system. It is a degenerative and slowly progressive disease. PD patients have difficulty at the beginning of the movement, at the path of movement, and at the end of the movement. PD consists of 5 main stages.

Methods: The purpose of this study was to diagnose PD type 1 and 2 on the electrical activity of shoulder muscle during isometric contraction with and without intellectual activity. In the same way, the electrical activity of the 2 right anterior deltoid muscles and the right upper trapezium by electromyographic apparatus in 4 conditions: (1) Resting, (2) Resting with intellectual activity, (3) performing an isometric movement in the hands, and (4) performing a movement Isometric in hand with an intellectual activity evaluated. The statistical population of the study consisted of 20 patients as experimental group (10 patients in the first stage and 10 patients in the second stage of PD) and ten healthy subjects as the control group as the statistical population. Shapiro-Wilk test was used to determine the normal distribution of data. Averages of variables were compared using the ANOVA test at a significant level of $5 \%$. All statistical methods were performed using SPSS software.

Results: The results of this study showed that the electrical activity of the shoulder belt muscles is significantly different during and after the isometric contraction with and without mental activity in PD type I and II.

Conclusion: As a result, a non-invasive approach to assessing the electrical activity of shoulder muscle can be used to determine the first and second stages of PD. Research shows that PD is a chronic and progressive complication that most affects older people. Also, according to the results, Parkinson's patients have weaker performance in cognitive functions than healthy people.

Keywords: Parkinson's disease; Electromyography; Shoulder muscle; Isometric contraction; Intellectual activity.
\end{abstract}

Citation: Sotoodeh R, Nowshiravan Rahatabad F, Jafarnia Dabanloo N. Diagnosis of Parkinson's disease type 1 and 2 on the electrical activity of hand muscle during isometric contraction with and without intellectual activity. Int Clin Neurosci J. 2020;7(1):26-30. doi:10.15171/icnj.2020.04.

\section{Introduction}

Parkinson's disease (PD) was first described by British scientist Dr. James Parkinson in 1817. The disease diminishes the amount of dopamine-mediated by the destruction of a part of the brain, called substantia nigra, that involved in the production of dopamine. Moreover, every one of thousands of people has a population of men and women and one out of one hundred people over the age of 75. Many factors have led to the prevalence and incidence of PD in different societies such as genetic and environmental factors such as positive family history, male gender, head trauma, and age. ${ }^{1,2}$

Sometimes in the early stages of PD, there is a type of disorder in a person 's motor function, which includes sleep disorders, cognitive disorders, and mood disturbances as well as intellectual deterioration. ${ }^{2,3}$

Symptoms of PD are local instability that usually occurs in the final stages of the disease, but may even affect those with early or mild symptoms.,

PD patients usually have difficulty moving. An important feature of this disease is resting tremor. There is a particular type of stiffness in the muscles that can affect both the flexor and extensor muscles so-called rigidities and usually occurs as a cogwheel phenomenon. Rigidity exacerbated by stress, anxiety, limb movement, or standing posture.

Stress is a specific symptom of $\mathrm{PD}$, which is considered one of the most common signs of PD. However, some of the people with PD have never encountered this problem. With the progress of the disease, involuntary movements

(C) 2020 The Author(s). This is an open access article distributed under the terms of the Creative Commons Attribution License (http:// creativecommons.org/licenses/by/4.0/), which permits unrestricted use, distribution, and reproduction in any medium, provided the original work is properly cited. 
like hand motion are reduced. ${ }^{6}$

Changes that occur with age in balance control systems decrease the ability of the elderly to maintain balance. Changes in the muscle-skeletal system, including reduction of proprioception and muscular endurance and flexibility, changes in the sensory system, including deep sensation, decreased visual acuity, and contrast sensitivity. Consequently, central nervous system changes, including decreased neurons and dendrites, decreased the number of giant pyramidal cells in the motor cortex, including changes that occur with age.?

The top - body studies in Parkinson's patients show that most of the patients are experiencing frequent vibration problems during the disease period, slow motion (bradykinesia), and the rigidity of the hand movement. According to some researchers, these moving disorders may consider as a substantial factor in the inability to cope with PD patients. The analysis of the EMG signals will be performed to investigate PD in the first and second stages of the disease. Therefore, the analysis of the EMG signals can provide new insight into $\mathrm{PD}$ and maybe a critical indicator of assessment, diagnosis, and improvement. ${ }^{6}$

According to epidemiological studies, $\mathrm{PD}$ is due to the collapse of the balance between the dopaminergic and clinical systems. This imbalance is due to a decrease in the activity of the dopaminergic system in the brain substances that block the brain's dopaminergic receptors can also cause states such as PD. ${ }^{8}$

In a study, measuring and analyzing single and multiple finger slashes in normal and Parkinson's subjects, they examined the timing and rhythm disorders in people with PD. In this study, the fingers of seven subjects with PD and ten normal subjects tested. The results showed that there was no evidence of increased variation in operation at specific frequencies. The acceleration velocity decreased to the maximum speed, which was seen only in Parkinson's subjects. ${ }^{9}$

In a study comparing balance in patients with stroke, Parkinson's, and multiple sclerosis (MS), patients with MS, $\mathrm{PD}$, and stroke (ST) concluded that potential disorders were due to impaired balance control system. This study evaluated the evaluation of pathologically specific balance disorders as well as the different effects of MS, PD, and ST on the ability to use sensory information to control balance. ${ }^{10}$

Hacker et $\mathrm{al}^{11}$ investigated the effects of deep brain stimulation in the development of a resting body in the early stages of PD. The results showed that the probability of infection of deep brain stimulation in the early stages of PD might slow the break-of process.

Pasquini et $\mathrm{al}^{12}$ performed a clinical and neurological study of tremor progression in the early stages of PD. They stated that resting tremor is one of the main symptoms of PD and the most common type of tremor in the early stages of PD. However, kinetic and postural vibration can affect approximately half of these patients and occur in the absence of rest.

Due to the mentioned issues, the consequences associated with the arm disorders, especially in the service delivery service, are more important and therefore important and necessary to accomplish this study. ${ }^{14,15}$

\section{Materials and Methods}

The present study is an applied research field in terms of subject and purpose. The study design was a comparison of two groups of Parkinson's patients in the first and second stages of the disease. For this purpose, the statistical population of this study included 20 patients as the experimental group (10 patients in the first stage of PD and ten patients in the second stage of PD) and ten healthy individuals as the control group. These 30 people were selected purposefully, after fully explaining the purpose and method of research and obtaining the consent form as a statistical sample, the electromyography machine examined the electrical activity of the shoulder muscles at the Payambar hospital. In order to select subjects, the random sampling method used. Twenty subjects with PD who were eligible selected as the subjects (Table 1).

After the initial selection of the subjects in a face-toface meeting, all subjects provided with written and oral information about the research, goals, and duration of the research. This information included a series of basic knowledge about the topic of the research, type of activities, familiarity with the tools, plan, timing of the research, goals, and the extent of the potential risks. Nutrition and dietary habits and smoking were asked to make no changes. Subjects were advised not to change their medication if they were taking anti-Parkinson medication. Subjects voluntarily participated in the study and could be discontinued without any restrictions.

The 8-channel electromyography Noraxon device (Figure 1) has been used in this study.

This device used to record the electrical activity of the shoulder girdle muscles that Include transmitter and receiver units. The transmitter unit, coupled with the amplifier unit next to each pair of electrodes, is capable of transmitting waves by antenna wirelessly up to $30 \mathrm{~m}$ from the transmitter unit. The distance from the center to the center of the electrodes was $20 \mathrm{~mm}$.

At first, the skin of the electrode site was removed from the hair and then cleaned with alcohol and sanding to reduce resistance. The pair of electrodes positioned along

Table 1. Statistical Description of the Subjects Properties in Terms of Central Indices and Dispersion

\begin{tabular}{lcccc}
\hline \multirow{2}{*}{ Group } & \multicolumn{4}{c}{ Indicator } \\
\cline { 2 - 5 } & No. & Age (y) & Weight $(\mathbf{k g})$ & Height $(\mathbf{c m})$ \\
\hline Group 1 & 10 & $75 \pm 0.5$ & $77 \pm 0.3$ & $163 \pm 0.6$ \\
Group 2 & 10 & $77 \pm 0.4$ & $75 \pm 0.4$ & $162 \pm 0.5$ \\
Group 3 & 10 & $76 \pm 0.7$ & $78 \pm 0.5$ & $160 \pm 0.4$ \\
\hline
\end{tabular}




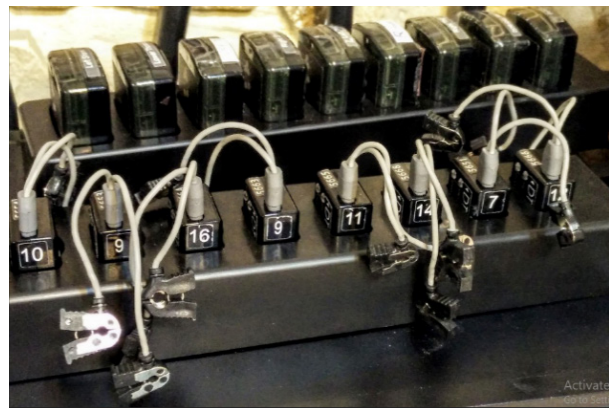

Figure 1. Eight-Channel Electromyography Noraxon Device.

the muscle line. The electrodes and cables were fixed to the skin to prevent disruption to the subject's motion and were bonded to prevent possible movement and disruption. The center-to-center distance of the electrodes was $2 \mathrm{~cm}$, and the EMG recorder electrode aligned to the SENIAM protocol. Since according to Murray et al, wrist extensors and biceps are clinically destructive and also have the most accessibility in surface electromyography, the electrodes are positioned on the muscle ventricle and along the muscle fibers. ${ }^{13}$

First, Initial analyses were performed on the recorded signals by Dialogue software. These analyzes included: sorting the signals and measuring them (40 seconds for each data record), calculating the average level of muscle activity at the time of data recording by calculating the square root of the second, 100-millisecond muscle activity signal. Then the average activity level using the mean muscle activity level in the data of maximum voluntary contraction and the lowest activity level, using the formula, normalized the level of muscle activity, meaning that the level of muscle activity at the time of data recording, in percent We expressed the most voluntary contraction of the muscle.

Shapiro-Wilk test was used to determine the natural

Table 2. Shapiro-Wilk Test for the Muscles in Running Isometric Movement in Parkinson's Patients in the First and Second Stages of the Disease

\begin{tabular}{lccc}
\hline \multirow{2}{*}{ Level } & \multicolumn{3}{c}{ Shapiro-Wilk Test } \\
\cline { 2 - 4 } & Statistics & df & Meaningful Level \\
\hline Group 1 & 0.914 & 28 & 0.073 \\
Group 2 & 0.902 & 28 & 0.051 \\
Control & 0.900 & 28 & 0.052 \\
\hline
\end{tabular}

distribution of data and used in the deductive statistics section of variance analysis with repeated measurements. Comparing the average variables using the ANOVA test was done at a significant level of 5\%. Excel was used to draw statistics and statistical analysis for parametric data of the ANOVA test and was used to compare and draw more accurate conclusions of Tokay and LSD. The significance level of $<0.05$ considered. All statistical methods were carried out using SPSS version 21 .

\section{Results and Discussion}

In this section, the hypotheses of the study were examined based on the data obtained from the sample. In all cases, ANOVA test was used to compare the mean between groups, and for comparison and conclusion, we used Tukey and LSD test.

\section{Disadvantages 1}

Null hypothesis: between the electromyography signals, there is no significant difference in the muscles in the hand movement of suffering in the first and second stages of the disease.

Based on the results of the Shapiro-Wilk test presented in Table 2, the data are normal.

The $P$ value obtained in Table 3 of ANOVA with the degree of freedom 28 at $P<0.05$ indicates that there is a difference between is 1 and group 2 during isometric movement of right anterior deltoid muscle during isometric movement. There was a significant difference in the level of right trapezius muscle activity when performing isometric movement between group 1 and group 2.

\section{Second Hypothesis}

Null hypothesis: between the electromyography signals, there is no significant difference in the muscles in the hand movement of suffering in the first and second stages of the disease.

As can be seen in Table 4, the $P$ value obtained from the ANOVA with 28 degrees of freedom at $P \geq 0.05$ indicates that there is a significant difference between group 1 during isometric movement and intellectual activity. Moreover, group 2 exists from the level of activity of the right anterior deltoid muscle. There was also a significant

Table 3. ANOVA test results to compare shoulder belt muscle activity during isometric movement in patients with PD in the first and second stages of the disease

\begin{tabular}{|c|c|c|c|c|c|c|c|}
\hline \multirow{2}{*}{\multicolumn{2}{|c|}{ Root mean square }} & \multirow{2}{*}{ Mean } & \multirow{2}{*}{ SD } & \multicolumn{2}{|c|}{$95 \% \mathrm{Cl}$} & \multirow{2}{*}{$d f$} & \multirow{2}{*}{$P$ value } \\
\hline & & & & Lower Bound & Upper Bound & & \\
\hline \multirow{3}{*}{$\begin{array}{l}\text { Right anterior } \\
\text { deltoid }\end{array}$} & Group 1 & 0.09397 & 0.12 & 0.2900 & -0.3579 & 28 & 0.001 \\
\hline & Group 2 & 0.19339 & 0.35 & 0.1305 & -0.5173 & 28 & 0.001 \\
\hline & Control & 0.05354 & 0.50 & 0.5546 & -0.5223 & 28 & 0.001 \\
\hline \multirow{3}{*}{$\begin{array}{l}\text { Right upper } \\
\text { trapezoid }\end{array}$} & Group 1 & 0.05155 & 0.53 & 0.3355 & -0.2465 & 28 & 0.001 \\
\hline & Group 2 & 0.13556 & 0.22 & 0.1645 & -0.4833 & 28 & 0.001 \\
\hline & Control & 0.04873 & 0.42 . & 0.1656 & -0.4253 & 28 & 0.001 \\
\hline
\end{tabular}


Table 4. ANOVA test results are used to compare the level of the activity of the shoulder - belt muscles while doing isometric movement and intellectual activity in suffering Parkinson's patients in the first and second stages of the disease

\begin{tabular}{|c|c|c|c|c|c|c|c|}
\hline \multirow{2}{*}{$\begin{array}{l}\text { Root mean } \\
\text { square }\end{array}$} & & \multirow{2}{*}{ Mean } & \multirow{2}{*}{ SD } & \multicolumn{2}{|c|}{$95 \% \mathrm{CI}$} & \multirow{2}{*}{$d f$} & \multirow{2}{*}{$P$ value } \\
\hline & & & & Lower Bound & Upper Bound & & \\
\hline \multirow{3}{*}{$\begin{array}{l}\text { Right anterior } \\
\text { deltoid }\end{array}$} & Group 1 & 0.04111 & 0.56 & 0.865 & -0.656 & 28 & 0.001 \\
\hline & Group 2 & 0.09354 & 0.05 & 0.254 & -0.465 & 28 & 0.001 \\
\hline & Control & 0.03165 & 0.22 & 0.366 & -0.256 & 28 & 0.001 \\
\hline \multirow{3}{*}{$\begin{array}{l}\text { Right upper } \\
\text { trapezoid }\end{array}$} & Group 1 & 0.04431 & 0.05 & 0.236 & -0.876 & 28 & 0.001 \\
\hline & Group 2 & 0.18251 & 0.01 & 0.121 & -0.663 & 28 & 0.001 \\
\hline & Control & 0.02365 & 0.98 & 0.356 & -0.369 & 28 & 0.001 \\
\hline
\end{tabular}

difference in the level of right trapezius muscle activity between group 1 and group 2.

Based on the results obtained from the Shapiro-Wilk test in Table 5, the data are normal.

\section{Third Hypothesis}

Null hypothesis: There was no significant difference between electromyographic signals in resting muscles in patients with $\mathrm{PD}$ in the first and second stages of the disease.

According to the results obtained from the Shapiro Wilk test, the data are normal (Table 6).

The $P$ value obtained from the ANOVA test presented in Table 7 with the degree of freedom 28 at $P \geq 0.05$ indicates that there is a significant difference in the level of right

Table 5. Shapiro-Wilk test for muscles to perform isometric movement and intellectual activity in suffering Parkinson's patients in the first and second stages of the disease

\begin{tabular}{lccc}
\hline \multirow{2}{*}{ Level } & \multicolumn{3}{c}{ Shapiro-Wilk Test } \\
\cline { 2 - 4 } & Statistics & df & Meaningful Level \\
\hline Group 1 & 0.924 & 28 & 0.053 \\
Group 2 & 0.811 & 28 & 0.141 \\
Control & 0.556 & 28 & 0.351 \\
\hline
\end{tabular}

Table 6. Shapiro-Wilk Test for Resting Muscles in Parkinson's Patients in Stages I and II

\begin{tabular}{lccc}
\hline \multirow{2}{*}{ Level } & \multicolumn{3}{c}{ Shapiro-Wilk Test } \\
\cline { 2 - 4 } & Statistics & $\mathbf{d f}$ & Meaningful Level \\
\hline Group 1 & 0.055 & 28 & 0.653 \\
Group 2 & 0.085 & 28 & 0.356 \\
Control & 0.054 & 28 & 0.344 \\
\hline
\end{tabular}

anterior deltoid muscle activity during rest between group 1 and group 2 during rest. There was a significant difference in the level of right trapezius muscle activity between group 1 and group 2 .

Fourth Hypothesis

Null hypothesis: Hypothesis Zero: There is no significant difference between electromyographic signals in resting muscles during exercise and intellectual activity in patients with PD in the first and second stages of the disease.

Based on the results obtained from the Shapiro - Wilk test presented in Table 8, the data are normal.

The $P$ values obtained from the ANOVA test given in Table 9 with the degrees of freedom at the level of $P \leq 0.05$ indicates that there is a significant difference during rest and performing an intellectual activity at the level of the right anterior cruciate ligament.

It can also observe at the level of the right - the right muscle between group 1 and group 2 .

\section{Conclusion}

According to the results of the tests, there was a significant

Table 8. Shapiro-Wilk test for the muscles of hand while resting and doing an intellectual activity in patients suffering Parkinson in the first and second stages of the disease

\begin{tabular}{lccc}
\hline \multirow{2}{*}{ Level } & \multicolumn{3}{c}{ Shapiro-Wilk Test } \\
\cline { 2 - 4 } & Statistics & df & Meaningful Level \\
\hline Group 1 & 0.066 & 28 & 0.887 \\
Group 2 & 0.052 & 28 & 0.802 \\
Control & 0.010 & 28 & 0.795 \\
\hline
\end{tabular}

Table 7. ANOVA test results in order to compare the activity level of the belt muscles during resting in Parkinson's patients in the first and second stages of the disease

\begin{tabular}{|c|c|c|c|c|c|c|c|}
\hline \multirow{2}{*}{$\begin{array}{l}\text { Root mean } \\
\text { square }\end{array}$} & & \multirow{2}{*}{ Mean } & \multirow{2}{*}{ SD } & \multicolumn{2}{|c|}{$95 \% \mathrm{Cl}$} & \multirow{2}{*}{$d f$} & \multirow{2}{*}{$P$ value } \\
\hline & & & & Lower Bound & Upper Bound & & \\
\hline \multirow{3}{*}{$\begin{array}{l}\text { Right anterior } \\
\text { deltoid }\end{array}$} & Group 1 & 0.08821 & 0.56 & 0.5552 & -0.2355 & 28 & 0.001 \\
\hline & Group 2 & 0.18552 & 0.10 & 0.6646 & -0.3545 & 28 & 0.001 \\
\hline & Control & 0.06254 & 0.54 & 0.5656 & -0.5589 & 28 & 0.001 \\
\hline \multirow{3}{*}{$\begin{array}{l}\text { Right upper } \\
\text { trapezoid }\end{array}$} & Group 1 & 0.05999 & 0.55 & 0.4892 & -0.2798 & 28 & 0.001 \\
\hline & Group 2 & 0.19766 & 0.07 & 0.1986 & -0.2245 & 28 & 0.001 \\
\hline & Control & 0.03896 & 0.11 & 0.1222 & -0.4461 & 28 & 0.001 \\
\hline
\end{tabular}


Table 9. ANOVA test results in order to compare the activity level of the belt muscles during resting and doing an intellectual activity in suffering Parkinson's patients in the first and second stages of the disease.

\begin{tabular}{|c|c|c|c|c|c|c|c|}
\hline \multirow{2}{*}{$\begin{array}{l}\text { Root mean } \\
\text { square }\end{array}$} & & \multirow{2}{*}{ Mean } & \multirow{2}{*}{ SD } & \multicolumn{2}{|c|}{$95 \% \mathrm{Cl}$} & \multirow{2}{*}{$d f$} & \multirow{2}{*}{$P$ value } \\
\hline & & & & Lower Bound & Upper Bound & & \\
\hline \multirow{3}{*}{$\begin{array}{l}\text { Right anterior } \\
\text { deltoid }\end{array}$} & Group 1 & 0.07121 & 0.45 & 0.6431 & -0.7863 & 28 & 0.001 \\
\hline & Group 2 & 0.2001 & 0.11 & 0.5454 & -0.8500 & 28 & 0.001 \\
\hline & Control & 0.06722 & 0.28 & 0.2125 & -0.5863 & 28 & 0.001 \\
\hline \multirow{3}{*}{$\begin{array}{l}\text { Right upper } \\
\text { trapezoid }\end{array}$} & Group 1 & 0.06654 & 0.14 & 0.6581 & -0.7110 & 28 & 0.001 \\
\hline & Group 2 & 0.1955 & 0.05 & 0.8643 & -0.6822 & 28 & 0.001 \\
\hline & Control & 0.03896 & 0.11 & 0.1222 & -0.4461 & 28 & 0.001 \\
\hline
\end{tabular}

difference in the level of the electrical activity of the anterior deltoid muscle as well as the right trapezius muscle during isometric movement between group 1 and group 2.

Also, it can be noted that there is a significant difference in the level of the electrical activity of the right anterior deltoid muscle and the upper trapezius muscle during isometric movement and a mental activity between group 1 and group 2.

There was also a significant difference in the level of the electrical activity of the right trapezius muscle and the right anterior deltoid muscle during isometric movement and a mental activity between group 1 and group 2 .

There was a significant difference in the level of the electrical activity of the right trapezius muscle during rest between group 1 and group 2 .

There was a significant difference in the level of the electrical activity of the right anterior deltoid muscle during rest and exercise of intellectual activity between group 1 and group 2 .

There was a significant difference in the level of the electrical activity of the right trapezius muscle between rest and group 2 during rest and exercise of brain activity. Based on the results obtained in this study, we conclude that there is a significant difference between shoulder girth muscle activity and exercise in the shoulder girdle muscle groups. Also, by studying parametric studies, it can conclude that the selected patients have carcinogenesis in comparison to people with poorer functional abilities. Taking care of the place and making the patients and their families aware of it can become a burden on the patient.

\section{Conflict of Interest Disclosures}

The authors declare that they have no conflict of interests.

\section{Ethical Statement}

The registration is entirely non-invasive and poses no risk to the individual and has described to everyone before the procedure and the consent of each individual has obtained.

\section{References}

1. Friedman JH, Brown RG, Comella C, Garber CE, Krupp LB, Lou JS, et al. Fatigue in Parkinson's disease: a review. Mov Disord. 2007;22(3):297-308. doi: 10.1002/mds.21240.

2. Friedman JH, Friedman H. Fatigue in Parkinson's disease: a nine-year follow-up. Mov Disord. 2001;16(6):1120-2. doi: 10.1002/mds. 1201.

3. Alves G, Wentzel-Larsen T, Larsen JP. Is fatigue an independent and persistent symptom in patients with Parkinson disease? Neurology. 2004;63(10):1908-11. doi: 10.1212/01. wnl.0000144277.06917.cc.

4. Bloem BR, Grimbergen YA, Cramer M, Willemsen M, Zwinderman AH. Prospective assessment of falls in Parkinson's disease. J Neurol. 2001;248(11):950-8. doi: 10.1007/ s004150170047.

5. Wood B, Walker R. Parkinson's disease: characteristics of fallers and non-fallers. Age Ageing. 2001;30(5):423-4. doi: 10.1093/ ageing/30.5.423.

6. Behbehani R, Abu Al-Hassan A, Al-Salahat A, Sriraman D, Oakley JD, Alroughani R. Optical coherence tomography segmentation analysis in relapsing remitting versus progressive multiple sclerosis. PLoS One. 2017;12(2):e0172120. doi: 10.1371/journal.pone.0172120.

7. Ashburn A, Stack E, Pickering RM, Ward CD. A communitydwelling sample of people with Parkinson's disease: characteristics of fallers and non-fallers. Age Ageing. 2001;30(1):47-52. doi: 10.1093/ageing/30.1.47.

8. Soliveri P, Brown RG, Jahanshahi M, Marsden CD. Effect of practice on performance of a skilled motor task in patients with Parkinson's disease. J Neurol Neurosurg Psychiatry. 1992;55(6):454-60. doi: 10.1136/jnnp.55.6.454.

9. Muir SR, Jones RD, Andreae JH, Donaldson IM. Measurement and analysis of single and multiple finger tapping in normal and Parkinsonian subjects. Parkinsonism Relat Disord. 1995;1(2):89-96. doi: 10.1016/1353-8020(95)00001-1.

10. Cattaneo D, Carpinella I, Aprile I, Prosperini L, Montesano A, Jonsdottir J. Comparison of upright balance in stroke, Parkinson and multiple sclerosis. Acta Neurol Scand. 2016;133(5):34654. doi: 10.1111/ane.12466.

11. Hacker ML, DeLong MR, Turchan M, Heusinkveld LE, Ostrem JL, Molinari AL, et al. Effects of deep brain stimulation on rest tremor progression in early stage Parkinson disease. Neurology. 2018;91(5):e463-e71. doi: 10.1212/wnl.0000000000005903.

12. Pasquini J, Ceravolo R, Qamhawi Z, Lee JY, Deuschl G, Brooks DJ, et al. Progression of tremor in early stages of Parkinson's disease: a clinical and neuroimaging study. Brain. 2018;141(3):811-21. doi: 10.1093/brain/awx376.

13. Murray AM, Bennett DA, Mendes de Leon CF, Beckett LA, Evans DA. A longitudinal study of parkinsonism and disability in a community population of older people. J Gerontol A Biol Sci Med Sci. 2004;59(8):864-70. doi: 10.1093/gerona/59.8.m864.

14. Sawamoto N, Piccini P, Hotton G, Pavese N, Thielemans K, Brooks DJ. Cognitive deficits and striato-frontal dopamine release in Parkinson's disease. Brain. 2008;131(Pt 5):1294-302. doi: 10.1093/brain/awn054.

15. Stocchi F, Brusa L. Cognition and emotion in different stages and subtypes of Parkinson's disease. J Neurol. 2000;247 Suppl 2:II114-21. doi: 10.1007/pl00022912. 